\title{
Evaluation of functional severity of coronary artery disease and fluid dynamics' influence on hemodynamic parameters: A review
}

\author{
Kalimuthu Govindaraju ${ }^{a, *}$, Irfan Anjum Badruddin ${ }^{a}$, Girish N. Viswanathan ${ }^{\text {, }}$, \\ S.V. Ramesh ${ }^{\text {, }}$, A. Badarudin ${ }^{\text {a }}$
}

\author{
${ }^{a}$ Department of Mechanical Engineering, University of Malaya, Kuala Lumpur, Malaysia \\ $\mathrm{b}$ Institute of Cellular Medicine, Newcastle University, Newcastle upon Tyne, United Kingdom \\ ' Department of Medicine, University Malaya Medical Centre, Kuala Lumpur, Malaysia
}

Received 24 October 2011; received in revised form 19 March 2012; accepted 28 March 2012 Available online 14 June 2012

\author{
KEYWORDS \\ Coronary artery; \\ Blood flow; \\ Stenosis; \\ FFR; \\ CFR; \\ CFD
}

\begin{abstract}
Coronary Artery Disease (CAD) is responsible for most of the deaths in patients with cardiovascular diseases. Diagnostic coronary angiography analysis offers an anatomical knowledge of the severity of the stenosis. The functional or physiological significance is more valuable than the anatomical significance of CAD. Clinicians assess the functional severity of the stenosis by resorting to an invasive measurement of the pressure drop and flow. Hemodynamic parameters, such as pressure wire assessment fractional flow reserve (FFR) or Doppler wire assessment coronary flow reserve (CFR) are well-proven techniques to evaluate the physiological significance of the coronary artery stenosis in the cardiac catheterization laboratory. Between the two techniques mentioned above, the FFR is seen as a very useful index. The presence of guide wire reduces the coronary flow which causes the underestimation of pressure drop across the stenosis which leads to dilemma for the clinicians in the assessment of moderate stenosis. In such condition, the fundamental fluid mechanics is useful in the development of new functional severity parameters such as pressure drop coefficient and lesion flow coefficient. Since the flow takes place in a narrowed artery, the blood behaves as a non-Newtonian fluid. Computational fluid dynamics (CFD) allows a complete coronary flow simulation to study the relationship between the pressure and flow. This paper aims at explaining (i) diagnostic modalities for the evaluation of the CAD and valuable insights regarding FFR in the evaluation of the functional severity of the CAD (ii) the role of fluid dynamics in measuring the severity of CAD.

(c) 2012 Associazione Italiana di Fisica Medica. Published by Elsevier Ltd. All rights reserved.
\end{abstract}

\footnotetext{
* Corresponding author. Tel.: +60 3 79674463; fax: +60 379675317.

E-mail address: grajukm@gmail.com (K. Govindaraju).
} 


\section{Introduction}

Blood flow pattern is linear in normal coronary artery and becomes non-linear when blood flows through a narrowed or stenosed artery. Most of the acute myocardial infarctions (heart attacks) are caused by non-obstructive vulnerable coronary atherosclerotic plaques by rupture of a thin fibrous cap covering fatty debris and subsequent thrombus formation and embolization [1].

Intravascular probes are widely used to analyze crosssectional anatomical images and measure hemodynamic parameters, such as velocity of the blood flow and pressure drops across the stenosis. Coronary angiography [1], intravascular ultrasound (IVUS) [2,3] and coronary computed tomography angiography (CCTA) [4] are some of the useful diagnostic techniques in the evaluation of the anatomical significance of the stenosis, whereas, FFR [5-8] and CFR $[1,8-10]$ are the most useful techniques in evaluating the physiological significance of the stenosis. In the next few paragraphs, we shall discuss some of the diagnostic modalities used to evaluate the severity of the coronary artery disease. The present review will highlight the importance of FFR over all other diagnostic techniques; the role of CFD analysis in coronary flow, and other functional significant hemodynamic parameters derived from the principles of fluid dynamics.

\section{Techniques to evaluate the anatomical significance of severe stenosis}

\section{Coronary angiography and CCTA}

Coronary angiography is a radiological study and the most common technique used to study coronary artery disease. It provides a $2 \mathrm{D}$ image representation of the $3 \mathrm{D}$ vascular lumen of the arterial wall (Fig. 1A). A limitation of this technique lies in its inability to provide the functional or physiological significance of lesion especially those of intermediate stenosis whose diameter is between $45 \%$ but $70 \%$ with normal artery $[1,4]$. Therefore, the assessment of an intermediate coronary artery stenosis severity still remains most difficult for cardiologists [1].

The eccentric lesions have maximum and minimum diameters, which differ significantly (apparently there are more than two diameters in a cross-section). In the conventional coronary angiography, it is extremely difficult to assess the severity of the stenosis, particularly, the arteries having multiple stenoses or diffused CAD. Further, coronary angiogram techniques overestimate or underestimate the severity of the stenosis.

The 64-slice CCTA scanners have the ability to acquire the images of the complete coronary artery tree (Fig. 1B). Quantitative coronary angiography (QCA) is carried out after receipt of the CCTA images on an offline workstation to assess the anatomical significance of the stenoses $[11,12]$.

\section{Intravascular ultrasound (IVUS)}

Cross-sectional anatomical imaging can be obtained from the IVUS (Fig. 1C). Since the IVUS offers greater sensitivity in terms of diagnosing the disease, it is widely used as a standard method for identifying anatomical atherosclerosis in vivo [2,3]. Regardless of the detailed anatomical and physiological information provided by the IVUS, there are some practical limitations, such as the inability to insert the catheter into the regions of excessively lengthy and complex vessels, calcified, noncalcified, fibrous stenosis, and in remarkably small arteries. Other limitations include non-uniform rotational distortion (NURD) with mechanical IVUS transducers and the distortion of the cross-sectional image if the IVUS catheter image plane is not perpendicular to the long axis of the vessel [1].

\section{Hemodynamic parameters assessing functional significance of stenosis severity}

\section{Coronary flow reserve (CFR)}

Coronary flow reserve (CFR) is defined as the ratio of hyperemic mean blood flow to the resting blood flow. The rate of flow through the coronary arteries is difficult to measure in the catheterization lab, but the flow velocity can be measured using the Doppler guide wire. This parameter usually called as coronary blood flow velocity reserve (CFVR). If the velocity distribution is uniform, the CFR is equal to CFVR [13]. Other non-invasive techniques used to assess the CFR are (i) Echocardiography (ii) Positron emission tomography (PET).

If the severity of the stenosis increases, CFR value will decreases [10] and vice versa.
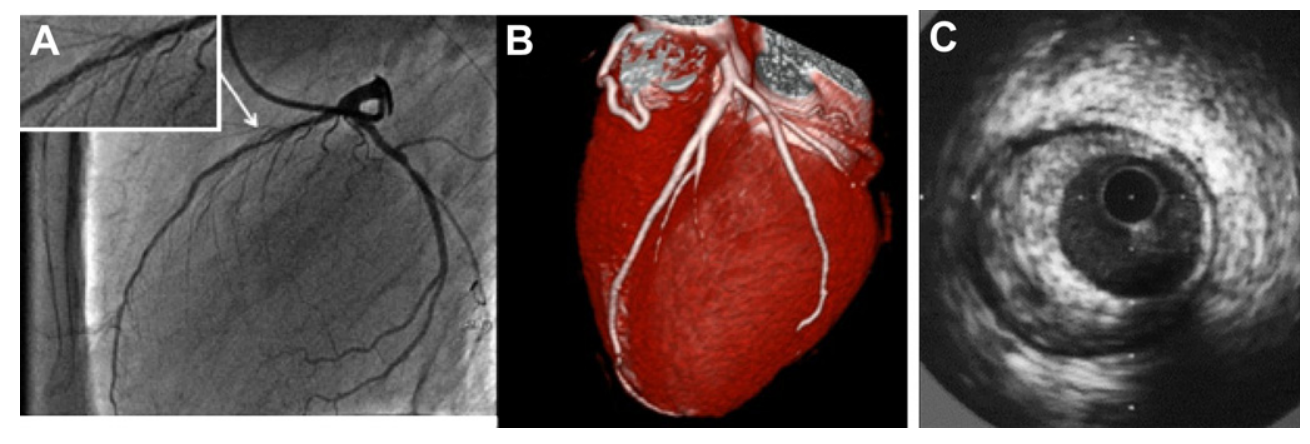

Figure 1 (A) Coronary angiography evaluation used to find anatomical significance of the stenosis (B) CCTA images used for the evaluation of severity of coronary artery stenosis (C) IVUS image shows stable and vulnerable plaque. 
A CFR value of $\leq 2.5$ has been identified as being functionally significant [14]. Normal coronary blood flow reserve is even higher due to the dilatation of the arterial lumen (well above 3 and up to 5). The CFR value depends upon both, the epicardial and the micro-vascular resistance, and this is also affected by myocardial chamber hypertrophy, diabetes, and age [1].

\section{Fractional flow reserve (FFR)}

In a stenosed coronary artery (Fig. 2A), the FFR is defined as the ratio between the maximal achievable coronary flow in the stenotic coronary artery $\left(Q_{\max s}\right)$ and the maximal flow in the same vessel if it were normal $\left(Q_{\max N}\right)$

$\mathrm{FFR}=\frac{Q_{\max S}}{Q_{\max N}}$
During hyperemic condition, myocardial resistances are minimal and remain constant. In addition to that the central venous pressure $\left(P_{v}\right)$ is assumed very small and hence neglected. Myocardial fractional flow reserve $\left(F F R_{\text {myo }}\right)$ is defined as the ratio between the distal pressure $P_{r}$ (which is measured remarkably close to the distal stenosis) and the proximal pressure $P_{e}$ (equivalent to mean aortic pressure $P_{a}$ ) of the stenosis $[1,6]$.

$\mathrm{FFR}_{\text {myo }}=\frac{P_{r}}{P_{e}}$

A suitable 0.014 inch wire with pressure sensors located at an offset distance of approximately $3 \mathrm{~cm}$ from the tip is inserted across the stenosis, and the absolute mean pressure $P_{e}$ and $P_{r}$ are recorded during rest and maximal hyperemia. The arterial hyperemia is induced through intravenous infusion of vasodilator medications like adenosine. A cut-off value FFR of 0.75 detects ischemia. Recent
A
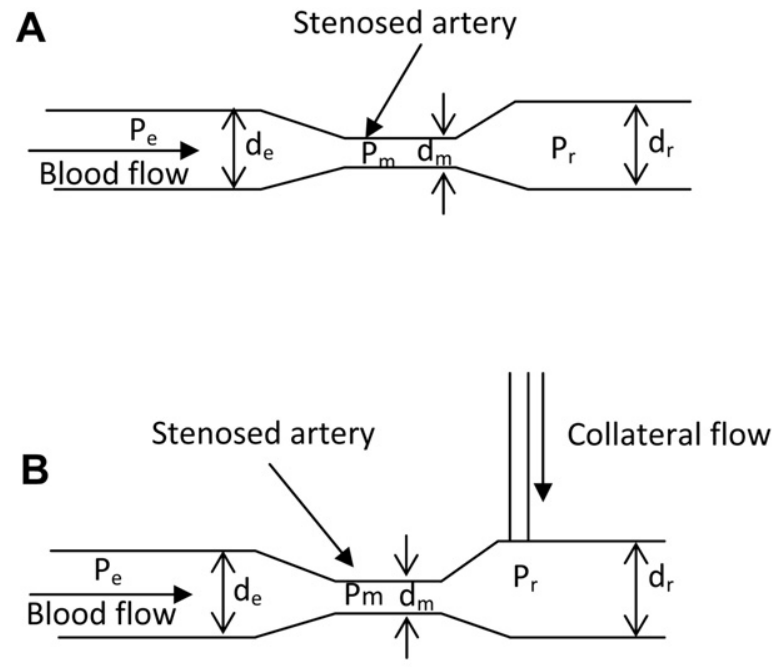

$\mathrm{P}_{\mathrm{e}}=$ Proximal pressure

$\mathrm{P}_{\mathrm{r}}=$ Distal Pressure

$P_{m}=$ Throat pressure

$\mathrm{FFR}=\mathrm{P}_{\mathrm{r}} / \mathrm{P}_{\mathrm{e}}$

$\mathrm{d}_{\mathrm{e}}=$ Proximal vessel diameter

$\mathrm{d}_{\mathrm{m}}=$ Throat region diameter

$\mathrm{d}_{\mathrm{r}}=$ Distal vessel diameter

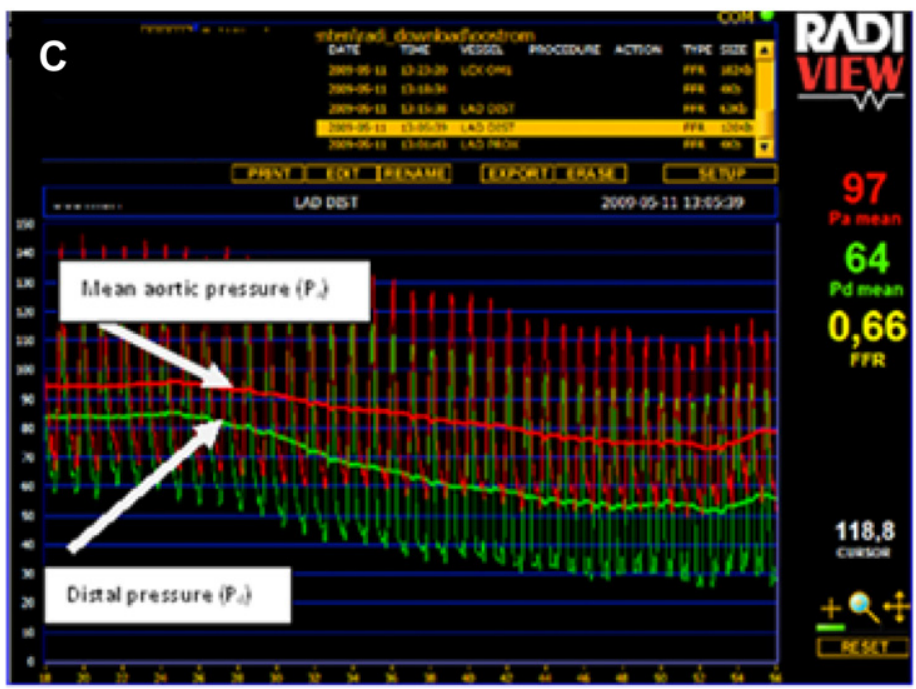

Figure 2 (A) Simplified schematic representation of stenosis geometry. $P_{e}$ and $P_{r}$ are measured by guiding catheter attached with a pressure sensor (B) Stenosis geometry with collateral flow, which masks the true severity of the stenosis (C) Typical example used to measure FFR, calculated as a ratio between the distal pressure $P_{r}$ and the mean aortic pressure $P_{a}$ measured in mmHg, FFR $=64 /$ $97=0.66$. 
studies show that an FFR of less than 0.8 is functionally significant. If FFR $<0.75$, then, angioplasty or coronary artery bypass graft (CABG) may be recommended $[5,15,16]$. If FFR $>0.8$, then, medical therapy may be recommended instead of surgical intervention and this may minimize unnecessary procedures. In the uncertainty region, the FFR value lies between 0.75 and 0.8 . The FFR measurement is also an extremely useful index for patients who suffer from multi-vessel disease. The FFR is independent of blood pressure, heart rate, and contractility [5,7].

In the FFR measurement, one needs to consider the downstream collateral flow (Fig. 2B). Due to this flow, the total flow increases in the downstream. This in turn, decreases the pressure drop across the stenosis. This affects the diagnostic parameter of the FFR. The presence of the collateral downstream flow increases the value of the FFR [17]. This increase in the FFR value masks the true severity of the stenosis and creates a dilemma for the physicians when the stenosis is moderate, or in the event of the FFR value being close to the cut-off value $(0.75)$. However, the FFR is not applicable to assess severity of serial stenoses. Since the physiological significance of each lesion is influenced by the presence of the other, it is impossible to measure the severity of each stenosis in a vessel having serial stenoses. True FFR of the selected lesion is defined as the FFR of the selected lesion if the other lesions are physically removed $[18,19]$.

\section{Why FFR is a superior diagnostic technique?}

FFR is easy to measure during coronary angiography and it is reproducible. It is linearly related to the maximum achievable blood flow. In contrast to CFR, the FFR has a unique value of 1 for every patient, every artery, and every segment [7]. If FFR $=0.6$, this means that the maximum achievable blood flow to the myocardium supplied by this artery is only $60 \%$ of what it would be if this coronary artery were quite normal. FFR is not influenced by a change in the hemodynamic conditions, such as heart rate, variations in blood pressure, and contractility [20]. FFR accounts for the interaction between the severity of the epicardial stenosis and the extension of the perfusion territory. For FFR, there is a sharp threshold value discriminating between the ischemic and non-ischemic stenosis. FFR measurement is also applicable to decisionmaking in patients with stent re-stenosis [21] and bifurcation lesion severity [22]

\section{Hemodynamic functional severity parameters derived from principles of fundamental fluid dynamics}

The true severity of artery stenosis can be assessed by pressure drop and flow. A sensor wire inserted across the coronary stenosis causes a reduction in coronary flow, alters the hyperemic pressure drop, and increases both, loss due to momentum change and viscous loss [23], which in turn leads to false FFR values. In addition to that, the accuracy of the FFR is limited by the assumption of zero venous pressure and minimal myocardial resistance at maximum hyperemia. CFR is not an independent index. It is highly dependent on the hemodynamic conditions [24].
Banerjee et al. [25], have developed diagnostic parameters such as a pressure drop coefficient $\left(\mathrm{CDP}_{\mathrm{e}}\right)$, and Lesion flow coefficient (LFC) $\tilde{c}$ which are derived from the fundamentals of fluid mechanics in a coronary artery having a single stenosis.

\section{Pressure drop coefficient $\left(\mathrm{CDP}_{\mathrm{e}}\right)$}

Consider Fig. 2A, $\mathrm{CDP}_{\mathrm{e}}$ is defined as the ratio of mean transstenotic pressure drop $(\Delta \bar{p})$ to proximal dynamic pressure. $\mathrm{CDP}_{\mathrm{e}}$ uses pressure and flow measurements to assess stenosis' severity and $\mathrm{CDP}_{\mathrm{e}}$ has an advantage here, of being able to delineate epicardial stenosis and micro-vascular disease [24].

$\mathrm{CDP}_{\mathrm{e}}=\Delta \overline{\mathrm{p}} /\left(0.5 \times \rho \times \overline{\overline{u_{e}^{2}}}\right)$

where $\rho$ is blood density $\mathrm{g} / \mathrm{cm}^{3}, \overline{\overline{u_{e}^{2}}}$ is spatial and temporal mean blood velocity $\mathrm{cm} / \mathrm{sec}$ in the proximal vessel, and $\Delta \bar{p}=\overline{P_{e}}-\overline{P_{r}}$ in $\mathrm{mm} \mathrm{Hg}, \mathrm{CDP}_{\mathrm{e}}$ depends on the geometry of the stenosis, flow rate, presence of the guide wire, and the flow pattern. Guide wire insertion affects viscous and momentum change losses. Further, Fig. 3 shows a correlation, based on three points' strains statistical reasoning. A relation has been provided by those authors' is used to measure $\mathrm{CDP}_{\mathrm{e}}$ and it is one of the factors to decide the severity of the stenosis.

\section{Lesion flow coefficient (LFC)}

Banerjee et al. [26] developed a normalized and nondimensional diagnostic parameter, lesion flow coefficient $\tilde{c}$ which combines hemodynamic and geometric parameters of coronary stenosis. In a stenosed artery, the LFC is defined as the ratio of percentage area stenosis $\times(1-k)$ to the square root of $\mathrm{CDP}_{\mathrm{m}}$ evaluated at the site of stenosis at hyperemia

$\tilde{c}=\frac{1-k}{A_{m}-A_{g}} \times \frac{\tilde{Q}}{(2 \Delta \tilde{p} / \rho)^{0.5}}$

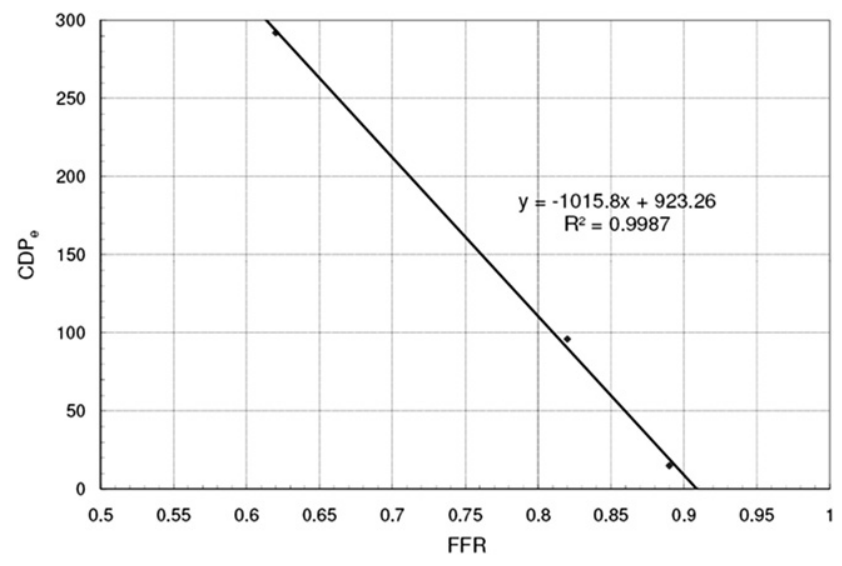

Figure 3 A relation between FFR and $\mathrm{CDP}_{\mathrm{e}}$. In intermediate stenosis, FFR is limited to a small range $(0.8-0.75)$, whereas, $\mathrm{CDP}_{\mathrm{e}}$ has a wide range. Therefore, a better and more accurate threshold value can be found for $\mathrm{CDP}_{\mathrm{e}}$ in human clinical trials. Banerjee, R.K., et al. [25]. 
where $k=\frac{A_{m}-A_{g}}{A_{e}-A_{g}}$

$A_{g}=$ area of the catheter; $A_{m}=$ Area of the throat; $A_{e}=$ Area of proximal.

In the absence of guide wire, $k$ is the ratio of area of $A_{m}$ to $A_{e}$. Since the $\tilde{c}$ correlates well with FFR, it is also one of the factors to find coronary stenosis severity and has been proven for the porcine model by Abhijit Sinha Roy et al. [27].

The influence of coronary collateral downstream flow affects $\mathrm{CDP}_{\mathrm{e}}$ and $\tilde{c}$. In this case, the $\mathrm{CDP}_{\mathrm{e}}$ decreases, whereas the LFC increases. The cut-off value for these parameters is yet to be determined in terms of a clinical evaluation [17].

\section{Effect of stenosis on blood behavior}

Blood mainly consists of plasma and red blood cells. When blood flows in the larger arteries, the shear rate is sufficiently high and it behaves like a Newtonian fluid [28]. However, if the flow occurs in a narrowed stenosed artery, the red cell particles' interactions are more, and the shear rate will be less than $100 \mathrm{~s}^{-1}$. The red cells tend to move outwards in the column of blood and thus, increase the viscosity of the blood. Under such conditions, blood behaves like a Non-Newtonian fluid [29]. The flow and shear rates are low in the outlet post-stenotically but are rather high in the inlet and bottlenecks of stenosis.

\section{Effect of stenosis on coronary flow}

The regulation of coronary flow is complex and goes beyond the arterial wall structure and elasticity. It comprises a complex pattern of neuro-humoral and local regulation, where the surrounding cardiac muscles play an important role. The difference in the material properties of the arterial wall elasticity are due to various factors, namely calcified plaque, rigidity of the wall due to arteriosclerosis, and blockage due to smooth muscle cell proliferation. All of these influence both, the pressure and flow behavior, thereby, affecting FFR, $\mathrm{CDP}_{\mathrm{e}}$, and LFC [30].

A non-dimensional frequency parameter or the Womersley parameter $(\alpha=R \sqrt{\omega / \nu}$, where $R$ is the artery radius, $\omega$ is the angular frequency, and $\nu$ is kinematic viscosity) highlights the relationship between the unsteady and viscous forces. The typical range of Reynolds numbers of blood flow in the body varies from 1 in small arterioles to approximately 4000 in the largest artery, the aorta [31] It is well-known that the Reynolds number and the frequency parameter values influence the pulsatile fluid flow. In a stenotic coronary flow, pressure losses generally depend on orifice shape and the upstream Reynolds number [31]. The mean proximal Reynolds number $\left(\tilde{R} e_{e}=4 \tilde{Q} / \pi d_{e} \nu\right.$, where $d_{e}$ is proximal vessel diameter and $\nu$ is kinematic viscosity) ranges from 100 to 230 and from 100 to 360 before and after coronary interventions for the pathophysiological flow. The Womersley number 2.25 was observed in patho-physiological conditions in native, intermediate, and residual lesions. In the presence of 0.35 and $0.46-\mathrm{mm}$ guide wires, the Womersley number was recorded as 1.99 and 1.9 , respectively [32].
Beyond these parameters, the velocity field and hence wall shear stress (WSS) is seen as being dependent on the flow wave form such as oscillatory, pulsatile, and physiological flows particularly downstream from the stenosis [33]. An unsteady pulsatile flow was reported from a mathematical model of tapered stenosed artery and surface irregularities of a complaint artery [34,35]. The presence of stenosis, vascular wall deformability, Tapering and irregular shaped constricted artery affect the axial velocity and radial velocity components of the streaming blood past a stenosed artery. The mechanical factors such as WSS, velocity distribution, flow separation, and secondary flow are of crucial importance for growth regulation and localization of plaque. Plaque accumulation is predominant at bends and bifurcations where blood flow is disturbed, where a secondary flow from the main vessel similar to collaterals is created, where flow separation regions are found $[36,37]$.

The thickness of plaque is only well correlated with shear rate and WSS in a model with fixed vessel size. The correlation between thickness of plaque and WSS is severely compromised in real coronary arteries due to noise generated by expansive remodeling. The velocity profile in the debulked artery is symmetric and well-ordered compared to a pre-debulked artery (debulking means atherectomy or balloon dilatation, invasive surgical procedure of removing plaques). WSS in the debulked artery is uniform and greater than the pre-debulked artery, which reduces plaque accumulation and arterial wall thickening in the arteries [38].

\section{CFD advantages in coronary flow}

Computational fluid dynamics (CFD) is a branch of fluid mechanics and has the ability to solve complex fluid flow problems by using numerical methods and algorithms. The CFD technique allows for the analysis of different clinical situations. It is useful in the study of coronary artery flows, instead of complicated and expensive in vivo measurements enabling quantification of the hemodynamic of healthy and diseased blood vessels. For example, a full hemodynamic analysis can be done if the stenosis geometry, coronary flow, and coronary pressure, etc. are known. The CFD simulations can be used to provide missing data such as WSS distribution, particle traces, Non-Newtonian importance factors, and other hemodynamic parameters to improve clinical decision-making and make it appropriate and accurate in both, the steady state and in transient simulations [29,39-41]. The computational approach has to be improved upon by considering anatomically correct geometric models, since a precise change in geometry can affect the flow field significantly.

The artery geometry, WSS, WSS gradient, and the oscillatory shear index are important risk factors in CAD. Since the coronary artery walls are small in size having approximately $3 \mathrm{~mm}$ in diameter, the CFD simulation is useful in assessing the risk factors [42]. Wellnhofer et al. [37] applied flow simulation studies and studied the impact of side branches on WSS in a reconstructed three-dimensional coronary geometry model from Biplane angiogram images 
and found that WSS distribution was non-linear and depended on geometric shapes.

It was found that the artery flow would be disturbed by the probe inserted into the artery. Tadaoka et al. [43] experimentally investigated the flow disturbance caused by a catheter in a straight pipe for various flow rates. The effect of intravascular probes in an idealized model of coronary artery of $180^{\circ}$ curved tube of $3 \mathrm{~mm}$ diameter was studied by Ryo Torii et al. [44] and found that the presence of the catheter altered the flow patterns, increased the pressure drop, and underestimated the velocity measurements during one cardiac cycle. These variations depended on the diameter of the catheter. The larger the diameter of the catheter, the greater the pressure drop and vice versa.

Stenosis' severity is measured by considering the pressure gradient and velocity of blood. The presence of a catheter in a coronary artery affects the pressure drop and flow, which are important diagnostic values and critical to the evaluation of functional severity of the lesion [25,44-46]. A single guide wire having a small diameter is essential to measure the severity effectively. The presence of the guide wire increases the mean hyperemic pressure drop $\left(\Delta p_{h}\right)$ across a moderate stenosis and decreases the mean hyperemic flow $\left(Q_{h}\right)$ [46]. A small change in the pressure drop and flow will highlight an uncertainty or misinterpret the severity of the moderate stenosis. In such conditions, the CFD technique proves to be a useful tool in the flow simulations undertaken to analyze the physical quantities.

Koo et al. [47] uses the CFD technique to measure FFR $\mathrm{CT}_{\mathrm{CT}}$ non-invasively from the reconstructed CCTA images with invasive FFR as a standard index. A spearman correlation coefficient, R of 0.72 (It means that $0.72 \times 0.72 \times 100=51.84 \%$ of the dependent variable is explained by the independent variable (Fig. 4). Moreover, $\mathrm{R}$ is a sample specific and might be even lower in other samples) has been provided by those authors at per-vessel level FFR $\mathrm{F}_{\mathrm{CT}}$ values with $\mathrm{FFR}$ values and minimal underestimation of FFR $\mathrm{R}_{\mathrm{CT}}$ with measured FFR were identified.

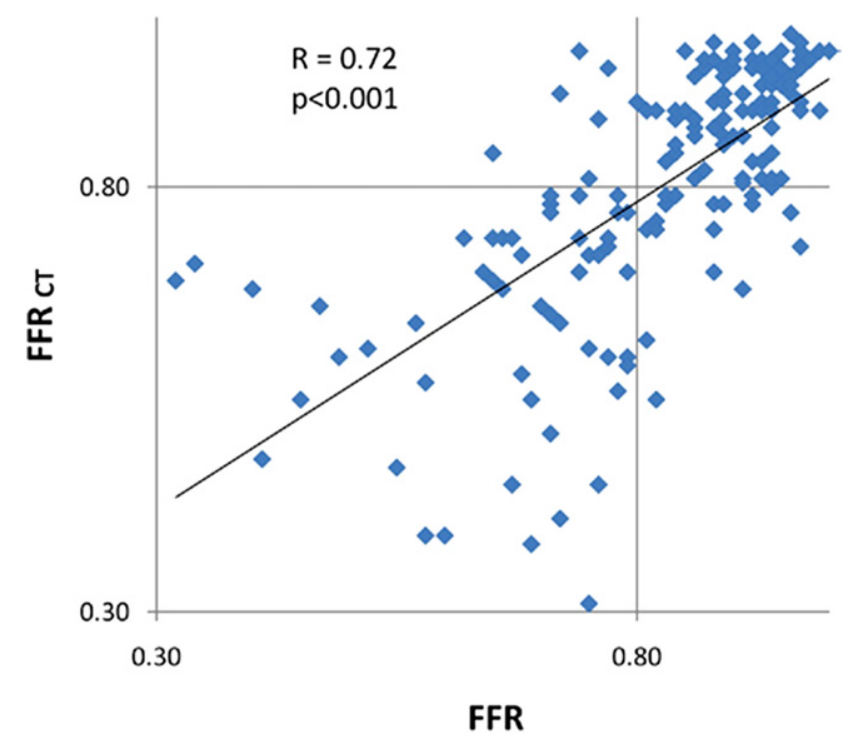

Figure 4 A relation between $\mathrm{FFR}_{\mathrm{CT}}$ and FFR. Koo et al. [47].
Since the flow is determined by the pressure gradient and resistance, the common fluid dynamic equation can be used to evaluate the pressure gradient in the stenosed artery $[9,48]$.

$\Delta \bar{p}=f \bar{Q}+s \bar{Q}^{2}$

$F=$ viscous friction, $S=$ Expansion loss, $\bar{Q}=$ mean arterial flow in $\mathrm{ml} / \mathrm{s}$.

A new technique has been proposed by $E$. Shalman et al. [48] to calculate the CFR and FFR and is based on pressure measurements in the artery proximal and distal to the stenosis. CFD calculations were made by $50 \%, 60 \%$, and $70 \%$ stenosis at various flow conditions. In their study, the pressure-based CFR correlates well with a flow-based CFR.

\section{Conclusion}

The present review evaluates the common techniques to find both physiological and functional severities of coronary artery disease and the role of fluid dynamics plays in the measurement of CAD. Nowadays, the FFR technique is deemed a standard index to identify the functional severity of the lesion and reduce unnecessary surgical complications in the artery. The area of the stenosis and the guide wire dimensions are responsible for pressure drop and flow reduction. Such changes create uncertainty in the measurement of FFR in the moderate (intermediate) stenosis. CFD is a finite volume, finite element, and finite difference technique, which is widely used to analyze the flow, pressure, velocity, and stress in a coronary artery model and can help identify the factors, which affect FFR measurements and predict clinical useful outcomes leading to the development of functional severity parameters $\mathrm{CDP}_{\mathrm{e}}$ and LFC, which are derived from fluid mechanics.

\section{References}

[1] Tobis J, Azarbal B, Slavin L. Assessment of intermediate severity coronary lesions in the catheterization laboratory. Journal of the American College of Cardiology 2007;49(8): 839-48.

[2] Nissen SE, Gurley JC. Application of intravascular ultrasound for detection and quantitation of coronary atherosclerosis. International Journal of Cardiac Imaging 1991;6(3-4):165-77.

[3] Nissen SE, Yock P. Intravascular ultrasound: novel pathophysiological insights and current clinical applications. Circulation 2001;103(4):604-16.

[4] Meijboom WB, Van Mieghem CA, van Pelt N, Weustink A, Pugliese F, Mollet NR, et al. Comprehensive assessment of coronary artery stenoses: computed tomography coronary angiography versus conventional coronary angiography and correlation with fractional flow reserve in patients with stable angina. Journal of the American College of Cardiology 2008; 52(8):636-43.

[5] Pijls NH, Van Gelder B, Van der Voort P, Peels K, Bracke FA, Bonnier $\mathrm{HJ}$, et al. Fractional flow reserve. A useful index to evaluate the influence of an epicardial coronary stenosis on myocardial blood flow. Circulation 1995;92(11):3183-93.

[6] Pijls NH, De Bruyne B, Peels K, Van Der Voort PH, Bonnier HJ, Bartunek JKJJ, et al. Measurement of fractional flow reserve to assess the functional severity of coronary-artery stenoses. New England Journal of Medicine 1996;334(26):1703-8. 
[7] Pijls NHJ, Bech GJW, De Bruyne B, van Straten A. Clinical assessment of functional stenosis severity: Use of coronary pressure measurements for the decision to bypass a lesion. The Annals of Thoracic Surgery 1997;63(6, Supplement 1): S6-11.

[8] Gould KL. Physiological severity of coronary artery stenosis. AJP: Heart and Circulatory Physiology 2006;291(6):H2583-5.

[9] MacCarthy P, Berger A, Manoharan G, Bartunek J, Barbato E, Wijns $\mathrm{W}$, et al. Pressure-derived measurement of coronary flow reserve. Journal of the American College of Cardiology 2005;45(2):216-20.

[10] Gould KL, Kirkeeide RL, Buchi M. Coronary flow reserve as a physiologic measure of stenosis severity. Journal of the American College of Cardiology 1990;15(2):459-74.

[11] Kristensen TS, Engstrøm T, Kelbæk $H$, von der Recke $P$, Nielsen MB, Kofoed KF. Correlation between coronary computed tomographic angiography and fractional flow reserve. International Journal of Cardiology 2010;144(2):200-5.

[12] van Werkhoven JM, Schuijf JD, Jukema JW, Pundziute G, de Roos A, Schalij MJ, et al. Comparison of non-invasive multislice computed tomography coronary angiography versus invasive coronary angiography and fractional flow reserve for the evaluation of men with known coronary artery disease. The American Journal of Cardiology 2009;104(5): 653-6.

[13] Shalman E, Rosenfeld M, Dgany E, Einav S. Numerical modeling of the flow in stenosed coronary artery. The relationship between main hemodynamic parameters. Computers in Biology and Medicine 2002;32(5):329-44.

[14] Serruys PW, di Mario C, Piek J, Schroeder E, Vrints C, Probst P, et al. Prognostic value of intracoronary flow velocity and diameter stenosis in assessing the short- and long-term outcomes of coronary balloon angioplasty: the DEBATE study (Doppler Endpoints Balloon Angioplasty Trial Europe). Circulation 1997;96(10):3369-77.

[15] Kern MJ, Samady H. Current concepts of integrated coronary physiology in the catheterization laboratory. Journal of the American College of Cardiology 2010;55(3):173-85.

[16] Hau W. Fractional flow reserve and complex coronary pathologic conditions. European Heart Journal 2004;25(9):723-7.

[17] Peelukhana SV, Back LH, Banerjee RK. Influence of coronary collateral flow on coronary diagnostic parameters: an in vitro study. Journal of Biomechanics 2009;42(16):2753-9.

[18] De Bruyne B, Pijls NH, Heyndrickx GR, Hodeige D, Kirkeeide R, Gould KL. Pressure-derived fractional flow reserve to assess serial epicardial stenoses: theoretical basis and animal validation. Circulation 2000;101(15):1840-7.

[19] Pijls NH, De Bruyne B, Bech GJ, Liistro F, Heyndrickx GR, Bonnier $\mathrm{HJ}$, et al. Coronary pressure measurement to assess the hemodynamic significance of serial stenoses within one coronary artery: validation in humans. Circulation 2000; 102(19):2371-7.

[20] de Bruyne B, Bartunek J, Sys SU, Pijls NH, Heyndrickx GR, Wijns W. Simultaneous coronary pressure and flow velocity measurements in humans. Feasibility, reproducibility, and hemodynamic dependence of coronary flow velocity reserve, hyperemic flow versus pressure slope index, and fractional flow reserve. Circulation 1996;94(8):1842-9.

[21] Kruger S, Koch KC, Kaumanns I, Merx MW, Hanrath P, Hoffmann R. Clinical significance of fractional flow reserve for evaluation of functional lesion severity in stent restenosis and native coronary arteries. Chest 2005;128(3):1645-9.

[22] Koo BK. Physiologic evaluation of bifurcation lesions using fractional flow reserve. Journal of Interventional Cardiology 2009;22(2):110-3.

[23] Rajabi-Jaghargh E, Kolli KK, Back LH, Banerjee RK. Effect of guidewire on contribution of loss due to momentum change and viscous loss to the translesional pressure drop across coronary artery stenosis: an analytical approach. BioMedical Engineering OnLine 2011;10(1):51.

[24] Banerjee RK, Ashtekar KD, Effat MA, Helmy TA, Kim E, Schneeberger EW, et al. Concurrent assessment of epicardial coronary artery stenosis and microvascular dysfunction using diagnostic endpoints derived from fundamental fluid dynamics principles. Journal of Invasive Cardiology 2009;21(10):511-7.

[25] Banerjee RK, Ashtekar KD, Helmy TA, Effat MA, Back LH, Khoury SF. Hemodynamic diagnostics of epicardial coronary stenoses: in-vitro experimental and computational study. Biomedical Engineering Online 2008;7:24.

[26] Banerjee RK, Sinha Roy A, Back LH, Back MR, Khoury SF, Millard RW. Characterizing momentum change and viscous loss of a hemodynamic endpoint in assessment of coronary lesions. Journal of Biomechanics 2007;40(3):652-62.

[27] Sinharoy A, Back M, Khoury S, Schneeberger E, Back L, Velury $\mathrm{V}$, et al. Functional and anatomical diagnosis of coronary artery stenoses. Journal of Surgical Research 2008; 150(1):24-33.

[28] Berger SA, Jou L-D. Flows in stenotic vessels. Annual Review of Fluid Mechanics 2000;32(1):347-82.

[29] Johnston BM, Johnston PR, Corney S, Kilpatrick D. Non-Newtonian blood flow in human right coronary arteries: transient simulations. Journal of Biomechanics 2006;39(6):1116-28.

[30] Konala BC, Das A, Banerjee RK. Influence of arterial wallstenosis compliance on the coronary diagnostic parameters. Journal of Biomechanics 2011;44(5):842-7.

[31] Ku DN. Blood flow in arteries. Annual Review of Fluid Mechanics 1997;29(1):399-434.

[32] Roy AS, Banerjee RK, Back LH, Back MR, Khoury S, Millard RW. Delineating the guide-wire flow obstruction effect in assessment of fractional flow reserve and coronary flow reserve measurements. American Journal of Physiology Heart and Circulatory Physiology 2005;289(1):H392-7.

[33] Siouffi M, Deplano V, Pélissier R. Experimental analysis of unsteady flows through a stenosis. Journal of Biomechanics 1997;31(1):11-9.

[34] Mandal PK. An unsteady analysis of non-Newtonian blood flow through tapered arteries with a stenosis. International Journal of Non-Linear Mechanics 2005;40(1):151-64.

[35] Chakravarty S, Mandal PK, Sarifuddin. Effect of surface irregularities on unsteady pulsatile flow in a compliant artery. International Journal of Non-Linear Mechanics 2005;40(10): 1268-81.

[36] Liepsch D. An introduction to biofluid mechanics-basic models and applications. Journal of Biomechanics 2002;35(4): 415-35.

[37] Wellnhofer E, Osman J, Kertzscher U, Affeld K, Fleck E, Goubergrits L. Flow simulation studies in coronary arteries-impact of side-branches. Atherosclerosis 2010;213(2): 475-81.

[38] Abraham JP, Sparrow EM, Lovik RD. Unsteady, threedimensional fluid mechanic analysis of blood flow in plaquenarrowed and plaque-freed arteries. International Journal of Heat and Mass Transfer 2008;51(23-24):5633-41.

[39] Perktold K, Hofer M, Rappitsch G, Loew M, Kuban BD, Friedman $\mathrm{MH}$. Validated computation of physiologic flow in a realistic coronary artery branch. Journal of Biomechanics 1997;31(3):217-28.

[40] Johnston BM, Johnston PR, Corney S, Kilpatrick D. Non-Newtonian blood flow in human right coronary arteries: steady state simulations. Journal of Biomechanics 2004;37(5): 709-20.

[41] Mallinger F, Drikakis D. Instability in three-dimensional, unsteady, stenotic flows. International Journal of Heat and Fluid Flow 2002;23(5):657-63.

[42] Knight J, Olgac U, Saur SC, Poulikakos D, Marshall Jr W, Cattin PC, et al. Choosing the optimal wall shear parameter 
for the prediction of plaque location-a patient-specific computational study in human right coronary arteries. Atherosclerosis 2010;211(2):445-50.

[43] Tadaoka S, Kagiyama M, Hiramatsu O, Ogasawara $Y$, Tsujioka K, Wada Y, et al. Accuracy of 20-MHz Doppler catheter coronary artery velocimetry for measurement of coronary blood flow velocity. Catheterization and Cardiovascular Diagnosis 1990;19(3):205-13.

[44] Torii R, Wood NB, Hughes AD, Thom SA, Aguado-Sierra J, Davies JE, et al. A computational study on the influence of catheter-delivered intravascular probes on blood flow in a coronary artery model. Journal of Biomechanics 2007; 40(11):2501-9.

[45] Meuwissen M, Siebes M, Chamuleau SA, van Eck-Smit BL, Koch KT, de Winter RJ, et al. Hyperemic stenosis resistance index for evaluation of functional coronary lesion severity. Circulation 2002;106(4):441-6.
[46] Sinha Roy A, Back LH, Banerjee RK. Guidewire flow obstruction effect on pressure drop-flow relationship in moderate coronary artery stenosis. Journal of Biomechanics 2006;39(5): 853-64.

[47] Koo B-K, Erglis A, Doh J-H, Daniels DV, Jegere S, Kim H-S, et al. Diagnosis of ischemia-causing coronary stenoses by noninvasive fractional flow reserve computed from coronary computed tomographic angiograms: results from the prospective multicenter DISCOVER-FLOW (Diagnosis of Ischemia-Causing Stenoses Obtained Via Noninvasive Fractional Flow Reserve) study. Journal of the American College of Cardiology 2011;58(19):1989-97.

[48] Shalman E, Barak C, Dgany E, Noskowitcz H, Einav S, Rosenfeld M. Pressure-based simultaneous CFR and FFR measurements: understanding the physiology of a stenosed vessel. Computers in Biology and Medicine 2001;31(5): 353-63. 